\section{Joël Bockaert}

\section{ADRESSE}

J. Bockaert : directeur de recherche au Cnrs. Cnrs UPR 9023, CCIPE, rue de la Cardo-

\title{
Les récepteurs à sept domaines transmembranaires: physiologie et pathologie de la transduction
}

Les récepteurs membranaires peuvent être regroupés en un petit nombre de familles, dont la plus nombreuse est certainement celle des récepteurs couplés aux protéines $G$ (RCPG), protéines monomériques caractérisées par leurs sept domaines transmembranaires. Elle comprend plusieurs centaines de membres, capables de reconnaître des messages très divers (photons, ions, acides aminés, etc.). Les RCPG sont des protéines de l'échange GDP/GTP au niveau des protéines $G$ hétérotrimériques $(\alpha \beta \gamma)$, et contrôlent un réseau de transduction via les sous-unités $\alpha$ de ces protéines, mais aussi via leur dimère $\beta \gamma$ (notamment l'activation de la protéine Ras). Des mutations somatiques ou héréditaires, activatrices ou inactivatrices, de ces RCPG sont responsables de nombreuses affections endocriniennes et métaboliques. En dehors de ces mutations, il est vraisemblable que le polymorphisme des gènes codant pour les RCPG puisse être à l'origine de différences individuelles dans la perception sensorielle (par exemple, vision, olfaction, gustation) ou d'autres fonctions du système nerveux.

'évolution des êtres multicellulaires est étroitement liée à la capacité qu'ont leurs cellules de communiquer entre elles. Cette communication est indispensable pour un développement harmonieux des cellules, pour le contrôle de leur division et la coordination de leurs activités. Les récepteurs des molécules de la commu- nication (hormones, neurotransmetteurs, facteurs de croissance, cytokines), comme ceux des messages venant de leur environnement (odeurs, molécules du goût, lumière...) sont, pour la plupart, membranaires (à l'exception notable des hormones stéroïdes et thyroïdiennes).

Durant les dix dernières années, la purification et surtout le clonage de 


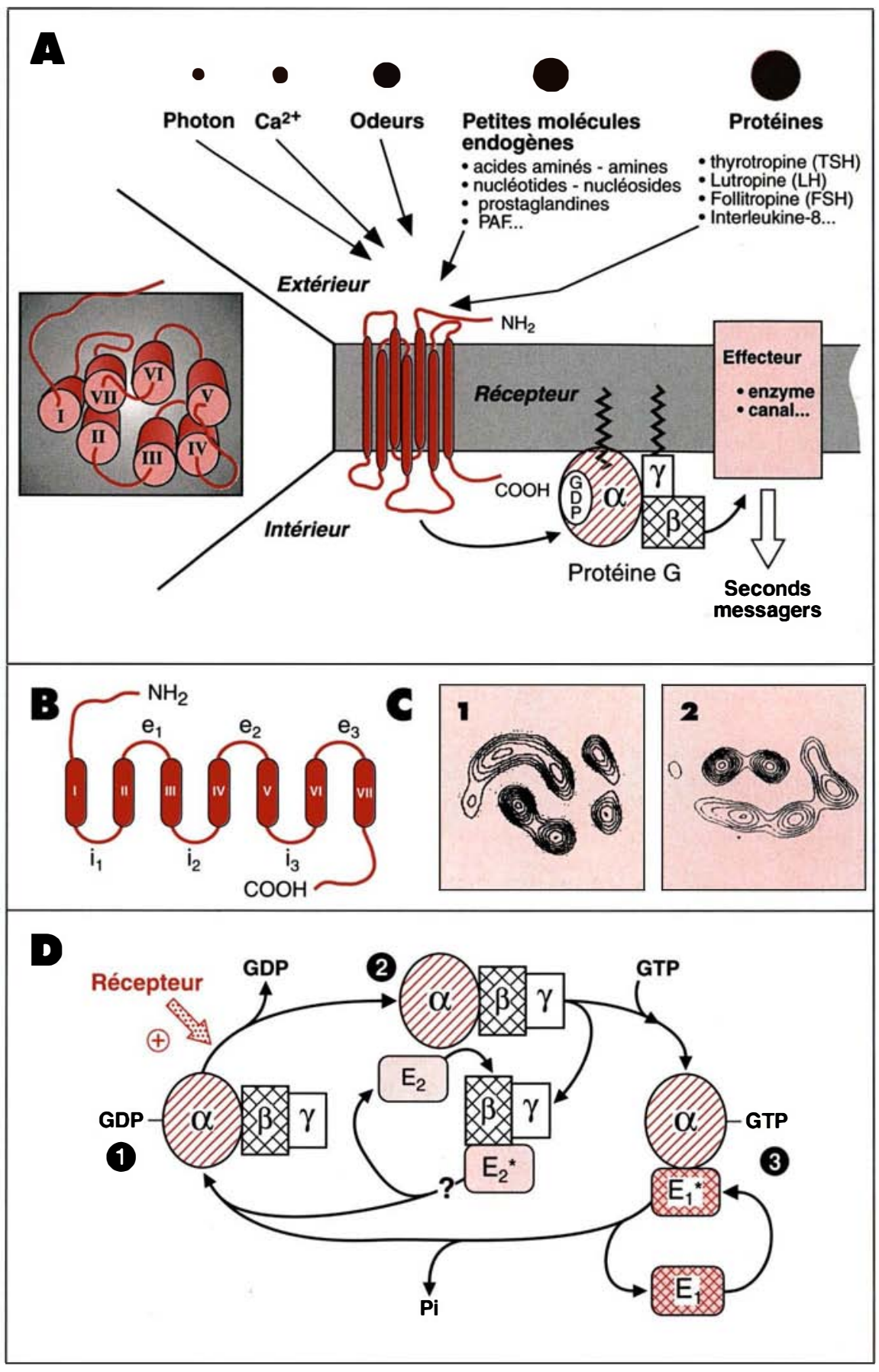

la majorité de ces récepteurs, a permis de montrer qu'ils appartiennent à un petit nombre de familles de protéines caractérisées à la fois par leur structure moléculaire et leur fonction: (1) récepteurs canaux, (2) récepteurs guanylate cyclase, tyrosine kinases et sérine/thréonine kinases, (3) récepteurs des cytokines activant des tyrosine kinases (Jak et Fyn ki- nases), (4) récepteurs couplés aux protéines liant le GTP ou protéines $G$ (RCPG).

\section{Utiliser un RCPG pour communiquer}

La famille des RCPG est la famille la plus nombreuse. Elle comprend plusieurs centaines de membres (dont le
Figure 1. Caractéristiques générales des récepteurs à sept domaines transmembranaires et de leur couplage aux protéines $\boldsymbol{G}$. A. A gauche, une vue de dessus et de trois quarts d'un récepteur à sept domaines transmembranaires (DT), numérotés de là VII. Noter le trièdre formé par les domaines I, II et VII. A droite, une vue de profil d'une membrane contenant un récepteur à sept domaines transmembranaires, une protéine $G$ hétérotrimérique $(\alpha, \beta, \gamma)$ et des effecteurs qui peuvent être des enzymes ladénylyl cyclase, phosphodiestérases, etc.) réglant la production de seconds messagers ou des canaux ioniques. La protéine $G$ est accrochée à la membrane par des lipides associés aux sous-unités $\alpha$ (myristate, palmitate) ou $\gamma$ (farnésyl, géranyl-géranyl). B. Nomenclature des domaines transmembranaires, des boucles internes et externes. C. Morphologie de la rhodopsine (1) et de la bactériorhodopsine (2) à une résolution de 9 Å. (Modifiée à partir de [6].) D. Cycle $d^{\prime}$ activation $d^{\prime} u n e$ protéine $G$ hétérotrimérique par un récepteur. La protéine $G$ hétérotrimérique est inactive dans l'état $n^{\circ} 1$ lla sous-unité $\alpha$ contient du GDP). Le récepteur stimule la libération du GDP. L'état $n^{\circ} 2$ est caractérisé par l'absence de nucléotides dans la sous-unité $\alpha$. Le récepteur est toujours associé à la protéine G. Il a généralement une plus forte affinité pour le ligand que lors de son association à la protéine $G$ dans l'état 1. Cet état 2 est très transitoire. Le GTP s'associe rapidement au site nucléotide vide. On observe alors la dissociation du récepteur, de la protéine $\alpha-G T P$, et du complexe $\beta y$ (état 3). $\alpha$ GTP, d'une part, et $\beta \gamma$, d'autre part, peuvent stimuler des effecteurs différents (respectivement $E^{* 1}$ et $E^{*} 2$ ). $L^{\prime} h y d r o l y s e d u$ GTP lié à $\alpha$ met fin à l'activation de l'effecteur E1. On ne sait pas comment l'activation de $E^{*} 2$ se termine (? sur la figure). groupe le plus nombreux est constitué par les récepteurs olfactifs [1, 2]). C'est certainement celle qui a su s'adapter le mieux au cours de l'évolution, étant capable de reconnaître des molécules messages ayant des structures des plus variées (photons, ions, molécules aromatiques diverses [odeurs], acides aminés et dérivés, nucléotides, nucléosides, lipides, 


\section{RÉFÉRENCES}

1. Buck L, Axel R. A novel multigene family may encode odorant receptors: a molecular basis for odor recognition. Cell 1991; 65 : 175-87.

2. Parmentier $M$, Vanderhaegen $P$, Schurmans S, Libert F, Vassart G. Génétique moléculaire des récepteurs olfactifs. médecine/ sciences 1994; 10: 1083-90.

3. Hibert MF, Hoflack J, Trumpp-Kallmeyer S, Bruinvels A. Modèles tridimensionnels des récepteurs couplés aux protéines $\mathrm{G}$. médecine/science 1993; 9: 31-40.

4. Zhou W, Flanagan C, Ballesteros JA, Konvicka $K$, Davidson JS, Weinstein $H$, Millar RP, Sealfon SC. A reciprocal mutation supports helix 2 and helix 7 proximity in gonodotropin-releasing hormone receptor. Mol Pharmacol 1994; 45 : 165-70.

5. Suryanarayana $S$, von Zastrow $M$, Kobilka BK Identification of intramolecular interactions in adrenergic receptors. $J$ Biol Chem 1992; 267: 21991-4.

6. Schertler GFX, Villa C, Henderson R. Projection structure of rhodopsin. Nature 1993 ; 362: 770-2.

7. Chardin P. Protéines ras et transmission des signaux mitogènes. médecine/sciences $1994 ; 10: 657-64$.

8. Bockaert J, Audigier Y, Homburger V, Rouot $B$. Les protéines $G$ de transduction. In: Landry Y, Gies J, eds. Paris: Arnette, 1993: 137-72.

9. Parenti M, Vigano $M$, Newman $\mathrm{CMH}$, Milligan G, Magee AI. A novel N-terminal motif for palmitoylation of G-protein $\alpha$ subunits. Biochem J 1993 ; 291 : 349-53.

10. Journot L, Pantaloni C, Poul MA, Mazarguil H, Bockaert J, Audigier Y. Aminoacids 367-376 of the $G s \alpha$ subunit induce membrane association when fused to the soluble amino-terminal deleted Gil $\alpha$ subunit. Proc Natl Acad Sci USA 1991 ; 88: 100548.

11. Chabre M, Deterre P. Molecular mechanism of visual transduction. Eur $J$ Biochem 1989 ; 179 : 255-6.

12. Bockaert J. G proteins and G-proteincoupled receptors: structure, function and interactions. Curr Op Neurobiol 1991 ; 1 : 3242.

13. Oliviera L, Paiva ACM, Sander C, Vriend G. A common step for signal transduction in $G$ protein-coupled receptors. peptides, protéines) (figure 1A). Les RCPG sont des protéines intramembranaires monomériques dont la séquence en acides aminés, déduite de la séquence nucléotidique des gènes correspondants, suggère la présence de sept domaines transmembranaires ayant chacun une structure en hélice $\alpha$ (I à VII) et reliés par 3 boucles externes (e1, e2, e3) et 3 boucles internes (i1, i2, i3) (figure 1B). Les hélices $\alpha$ sont étroitement accolées, définissant une fente centrale diédrique étroite et profonde de $20 \AA$ [3]. Il a été établi que dans le groupe I des RCPG (voir figure $2 A$ ), les domaines transmembranaires II et VII sont probablement en contact direct, par l'intermédiaire de deux résidus très conservés, un résidu aspartyl (D) du domaine transmembranaire II et un résidu asparaginyl (N), du domaine VII. On peut inverser ces deux résidus sans perdre la liaison du ligand, donc la structure du récepteur, alors que les remplacer par deux résidus aspartyl, ou deux résidus asparaginyl, la supprime [4]. Des expériences similaires indiquent que les domaines I et VII sont aussi voisins [5], suggérant que les domaines transmembranaires I, II et VII forment un trièdre (figure 1A). Il faut indiquer ici que cette structure à sept domaines transmembranaires est spéculative pour la majorité des récepteurs. Elle est fondée sur l'analyse d'hydropathie de la protéine et sur des expériences de mutagenèse similaires à celle que je viens de décrire. On possède davantage d'informations sur la structure de la rhodopsine, le récepteur de la phototransduction localisé dans les disques des bâtonnets rétiniens. Il s'agit d'un récepteur à sept domaines transmembranaires qui contient tous les acides aminés et les séquences consensus du groupe I des RCPG (figure 2). Un cristal bidimensionnel de la protéine a été obtenu [6]. L'analyse en microscopie électronique a permis d'obtenir une morphologie de ce récepteur à une résolution de $9 \AA$ et de la comparer à celle de la bactériorhodopsine (figure $1 C$ ) [6], une protéine à sept domaines transmembranaires qui n'est pas un RCPG mais une pompe à protons n'ayant pas d'homologie avec les RCPG au niveau de sa séquence en acides aminés. Pour la rhodopsine, les quatre pics de densi- té électronique représentent les quatre hélices orientées perpendiculairement à la membrane, l'arc le plus allongé représenterait les trois autres hélices ayant une orientation plus inclinée par rapport à la membrane. On voit dans la figure $1 C$ que la morphologie de la bactériorhodopsine est plus allongée et moins large, suggérant un arrangement différent des hélices dans ces deux protéines.

La fonction essentielle des RCPG est d'assurer la reconnaissance du signal externe et de catalyser l'échange GDP/GTP au niveau du site nucléotidique des protéines $G$ hétérotrimériques auxquelles ils sont associés. Les RCPG sont donc des protéines d'échange ayant un rôle identique aux protéines d'échange des petites protéines $\mathrm{G}$ monomériques de type Ras (par exemple Sos ou Ras GRF) [7]. Les protéines $G$ hétérotrimériques sont composées d'une sousunité $\alpha$ et d'un dimère $\beta \gamma$ indissociable (figure 1D). Ce sont des protéines sous-membranaires associées à la membrane par des lipides [8] (figure $1 A, D$ ). Le dimère $\beta \gamma$ est associé à la membrane par un lipide de type isoprène. Il s'agit d'un farnésyl (sous-unité $\gamma 1$ de la transducine) ou d'un géranyl-géranyl (autre sousunité $\gamma$ ) fixé par une liaison covalente à une cystéine carboxyméthylée constituant le résidu C-terminal de la sous-unité $\gamma$ [8]. Les sous-unités $\alpha$ sont associées à la membrane par un acide myristique (fixé sur une glycine en position 2 par une liaison d'amidation dans $\alpha$ i et $\alpha o$ ) et par un acide palmitique ( $\alpha$ s, $\alpha \mathrm{i}, \alpha \mathrm{o})$ ou deux ( $\alpha \mathrm{q}$, $\alpha 11$ ), fixés par une liaison thioester sur des résidus cystéyl localisés dans le domaine N-terminal [9]. Une séquence (Val-Asp-Thr-Glu-Asn-Ile-ArgArg-Val-Phe) située du côté C-terminal d' $\alpha$ s serait aussi importante pour son association à la membrane [10]. Lorsqu'un agoniste occupe un RCPG, celui-ci s'associe à la forme GDP de la protéine $G$ hétérotrimérique (état 1 , figure $1 D$ ), la sous-unité $\alpha$ perd son affinité pour le GDP, un état intermédiaire (RCPG- $\alpha \beta \gamma)$ se forme (état 2, figure $1 D$ ) pendant lequel la protéine $\alpha$ ne lie plus aucun nucléotide. Le récepteur possède alors, dans la plupart des cas, une forte affinité pour le ligand, plus forte que dans l'état 1 [11]. Cet état est ex- 


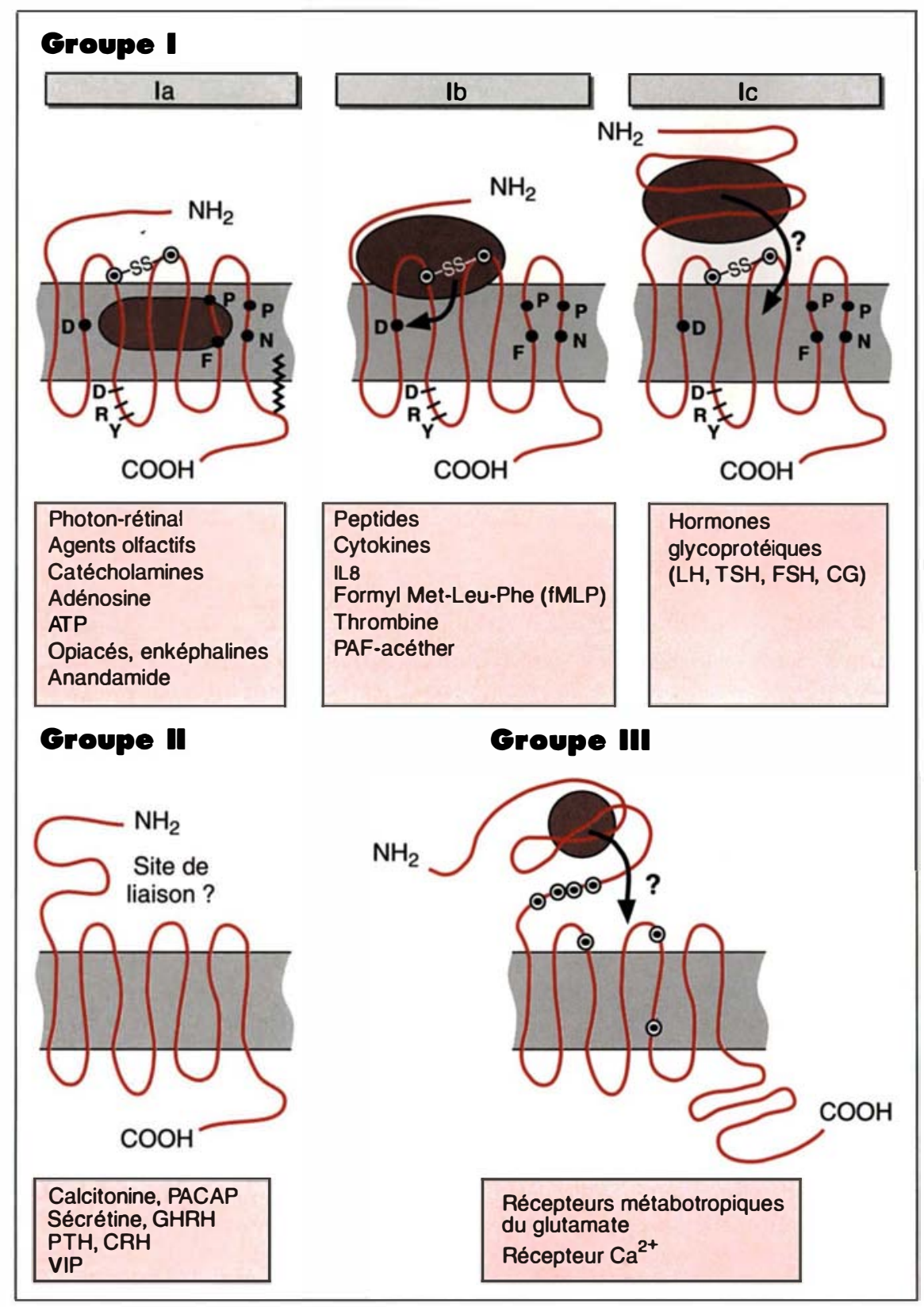

Figure 2. Classification des RCPG. Groupe I. Ce groupe contient la grande majorité des RCPG. II se caractérise par la présence d'une séquence de type DRY (aspartyl-arginyl-tyrosyl) ou ERW (glutamyl-arginyl-tryptophanyl) du côté N-terminal de i2 et certains acides aminés très conservés. D (aspartyl) dans les domaines transmembranaires (DT) II, N (asparaginyl) dans le DTVII, $P$ (prolyl) et $F$ (phénylalanyl) dans le DTVI. Un pont disulfure (S-S) entre deux résidus cystéyl relie les boucles e1 et e2. Ce groupe peut être divisé en trois sous-groupes, la, Ib, Ic selon la localisation probable du site de liaison des agonistes: entre les domaines transmembranaires pour la, plus extérieur et impliquant le domaine $\mathrm{N}$ terminal pour lb et au niveau du domaine $N$-terminal pour Ic. On ne sait pas si, une fois l'agoniste fixé sur le domaine $\mathrm{N}$-terminal des récepteurs du groupe Ic, il y a interaction de ce complexe avec les domaines transmembranaires ( $\rightarrow$ ?). Dans le groupe la, un résidu cystéyl est bien conservé dans la partie C-terminale, juste après le domaine transmembranaire VII. II est palmitoylé dans les récepteurs adrénergiques (m). Groupe II. Les récepteurs de ce groupe se distinguent de ceux du groupe I par l'absence d'analogie de séquence, notamment l'absence de séquence DRY. On ne sait pas où est situé le site de liaison des agonistes. Groupe III. Ce groupe contient les récepteurs métabotropiques du glutamate et le récepteur $\mathrm{Ca}^{2+}$. Le site de reconnaissance du ligand implique le domaine $N$-terminal. On ignore s'il implique aussi les domaines transmembranaires $(\rightarrow$ ?). Ces récepteurs contiennent 20 résidus cystéyl bien conservés $(\mathrm{O})$. LH: luteneizing hormone; TSH: thyroid stimulating hormone; $F S H$ : follicle stimulating hormone; $C G$ : chorionic gonadotrophin ; GHRH: growth hormone releasing hormone; $\mathrm{CRH}$ : corticotropin releasing hormone; PACAP: pituitary adenylate cyclase activating polypeptide; PTH: parathyroid hormone; VIP: vasoactive intestinal peptide.

trêmement transitoire, le GTP occupe alors le site nucléotidique resté vide. L'entrée du GTP provoque la dissociation des trois partenaires, le $\mathrm{RCPG}, \alpha$ et $\beta \gamma$. Il y a encore deux ans, on pensait que seule la sous-unité $\alpha$ ayant lié le GTP était capable de stimuler un ou plusieurs effecteurs; on sait aujourd'hui que le dimère $\beta \gamma$ a, lui aussi, cette capacité (figure 1D). L'hydrolyse du GTP, parfois stimulée par l'effecteur, marque la fin de l'ac$\mathrm{m} / \mathrm{s} n^{\circ} 3$, vol. 11 , mars 95 tivation de l'effecteur par la sous-unité $\alpha$. On ne sait pas bien comment se termine l'activation de l'effecteur stimulé par le dimère $\beta \gamma$ (figure $1 D$ ).

\section{Des gènes différents mais une même topologie}

On peut classer ces récepteurs en trois groupes (I, II, III) en tenant compte de deux critères principaux: leur séquence primaire et la localisation du site de liaison des agonistes. La plus grande différence entre ces trois groupes est l'absence d'analogie de leur séquence primaire en acides aminés. Si les gènes codant pour ces récepteurs ont évolué à partir d'un ancêtre commun, la divergence a dû avoir lieu très tôt au cours de l'évolution; s'il s'agit d'évolutions convergentes, on peut être intrigué par la pression de sélection qui a retenu 


\section{RÉFÉRENCES}

14. Tota MR, Strader CD. Characterization of the binding domain of $\beta$-adrenergic receptor with the fluorescent antagonist carazolol. Evidence for a buried ligand binding site. J Biol Chem 1990; 265 : 16891-7.

15. Fong TM, Huang RRC, Strader CD. The extracellular domain of the neurokinin-1 receptor is required for high-affinity binding of peptides. Biochemistry 1992; 31 : 11806-11.

16. Gerszten RE, Chen JI, Ishll $M$, Wang $L$, Nanevicz T, Turck CW, Vu TH, Coughlin SR. Specificity of the thrombin receptor for agonist peptide is defined by its extracellular surface. Nature $1994 ; 368$ : 648-51.

17. Nagayama Y, Wadsworth HL, Chazenbalk GD, Russo D, Seto P, Rapoport B. Thyrotropin-luteinizing hormone/chorionic gonadotropin receptor extracellular domain chimeras as probes for thyrotropin receptor function. Proc Natl Acad Sci USA 1991; 88: 902-5.

18. Nakanishi S. Molecular diversity of glutamate receptors and implications for brain function. Science 1992; 258: 597-603.

19. Pin JP, Duvoisin R. The metabotropic glutamate receptors: structure and functions. Neuropharmacology 1995 (sous presse).

20. Brown EM, Gamba G, Riccardi D, Lombardi M, Butters $R$, Kifor $O$, Sun A, Hediger MA, Lytton J, Hebert SC. Cloning and characterization of an extracellular $\mathrm{Ca}^{+}$-sensing receptor from bovine parathyroid. $\mathrm{Na}$ ture 1993; 366: 575-80.

21. Parmentier M, Libert F, Vassart G. La famille des récepteurs couplés aux protéines $\mathrm{G}$ et ses orphelins. médecine/sciences 1995; $11: 222-31$.

22. Matsuda LA, Lolait SJ, Brownstein MJ, Young AC, Bonner TI. Structure of a cannabinoid receptor and functional expression of the cloned CDNA. Nature $1990 ; 346: 561$ 4.

23. Devane WA, Hanus L, Breuer A, Pertwee R, Stevenson LA, Griffin G, Gibson D, Mandelbaum A, Etinger A, Mechoulam R. Isolation and structure of the brain constituent that binds to the cannabinoid receptor. Science 1992; 258: 1946-9.

24. Gether $U$, Johansen TE, Snider RM, Lowe III JA, Nakanishi S, Schwartz TW. Different binding epitopes on the NKI receptor for substance $P$ and a non-peptide anta-

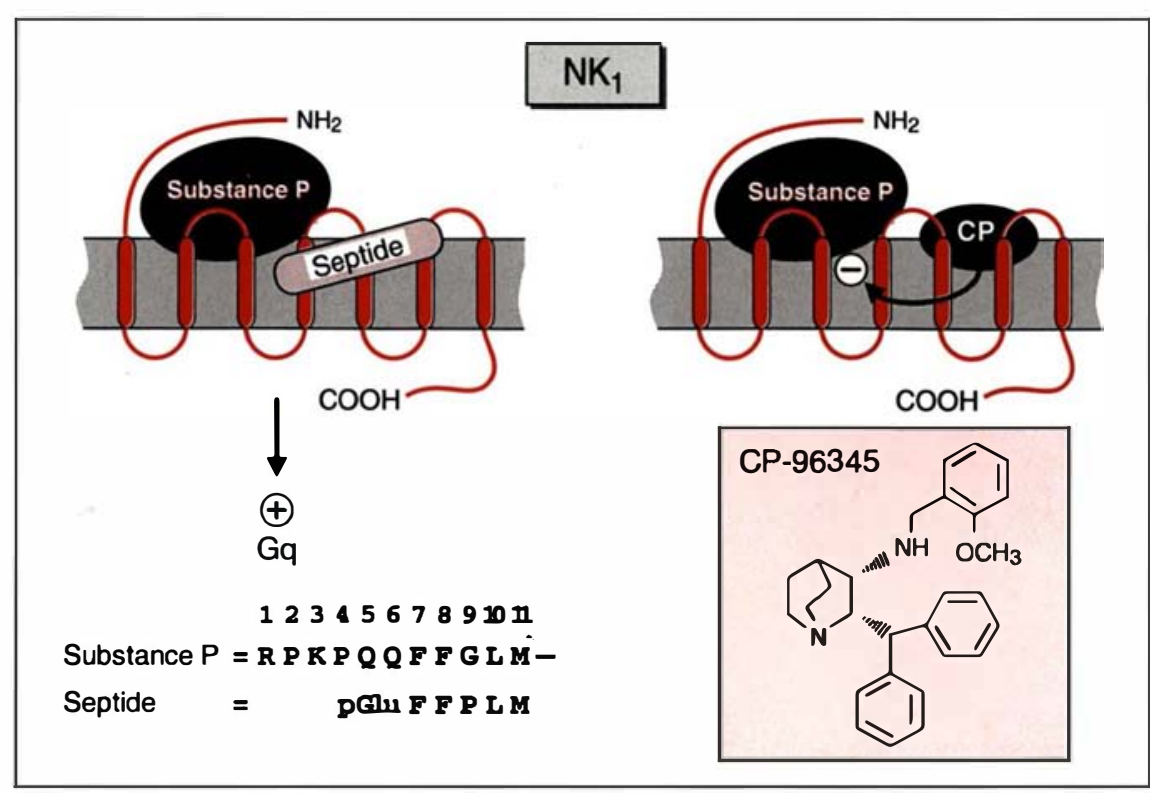

Figure 3. Sites allostériques putatifs du récepteur de la substance $P$ (NK1). Deux agonistes, un naturel (la substance $P$ ) et l'autre synthétique (septide) activent, en se fixant sur deux segments différents, le couplage du récepteur NK1 à la phospholipase $C$, via la protéine $G$ de type $G q$. La substance $P$ et un antagoniste non peptidique de la substance $P$ (le CP 96345) ne se fixent pas sur le même sous-site. Les séquences de la substance $P$ et du septide sont données en utilisant le code à une lettre des acides aminés. pGlu: $p$ signifie pyro et Glu est en toutes lettres car le premier acide aminé est pyro Glu pour lequel il n'y a pas de lettre code.

une topologie à sept domaines transmembranaires.

Le groupe I comprend la majorité des RCPG, y compris les récepteurs olfactifs [1]. Les prototypes dans ce groupe sont la rhodopsine et le récepteur $\beta$-adrénergique $[3,8,12$, 13]. Le groupe I peut être divisé en 3 sous-groupes (figure 2), selon la localisation probable du site de liaison des agonistes: (1) le sous-groupe Ia dans lequel le site de liaison est localisé dans la fente constituée par les domaines transmembranaires [3] (à une distance de $11 \AA$ de la membrane pour le récepteur $\beta$-adrénergique [14]). Il comprend les récepteurs des petits ligands (figure 2), y compris le rétinal, les catécholamines, les composés aromatiques [13]; (2) le sous-groupe Ib, dans lequel le site de liaison implique le do maine $\mathrm{N}$-terminal proche de la membrane, les boucles externes et certainement la partie externe de la poche délimitée par les domaines transmembranaires $[15,16]$. Il comprend les récepteurs des peptides, de certaines cytokines et de la thrombine; (3) le groupe Ic comprend les récepteurs des hormones glycoprotéiques (thyrotropine: TSH, lutropine: $\mathrm{LH}$, follitropine: $\mathrm{FSH}$, choriogonatropine: CG) (figure 2). Le domaine N-terminal qui fixe ces hormones est très long (350-400 acides aminés) et contient des séquences répétées de 20 acides aminés riches en leucine [17]. Le complexe, formé par les hormones glycoprotéiques et le domaine $\mathrm{N}$-terminal, joue peutêtre le rôle d'agoniste d'un site de liaison-transduction situé au sein des domaines transmembranaires [12] (figure 2).

L'alignement des séquences des récepteurs du groupe I a permis de déterminer des acides aminés et séquences consensus suivants (figure 2): (a) un résidu aspartyl du domaine transmembranaire II (D) est important pour la régulation allostérique de certains récepteurs par les cations monovalents, les protons ou le GTP (discuté par [4]). Nous avons déjà discuté les expériences suggérant son interaction avec un résidu asparagi- 


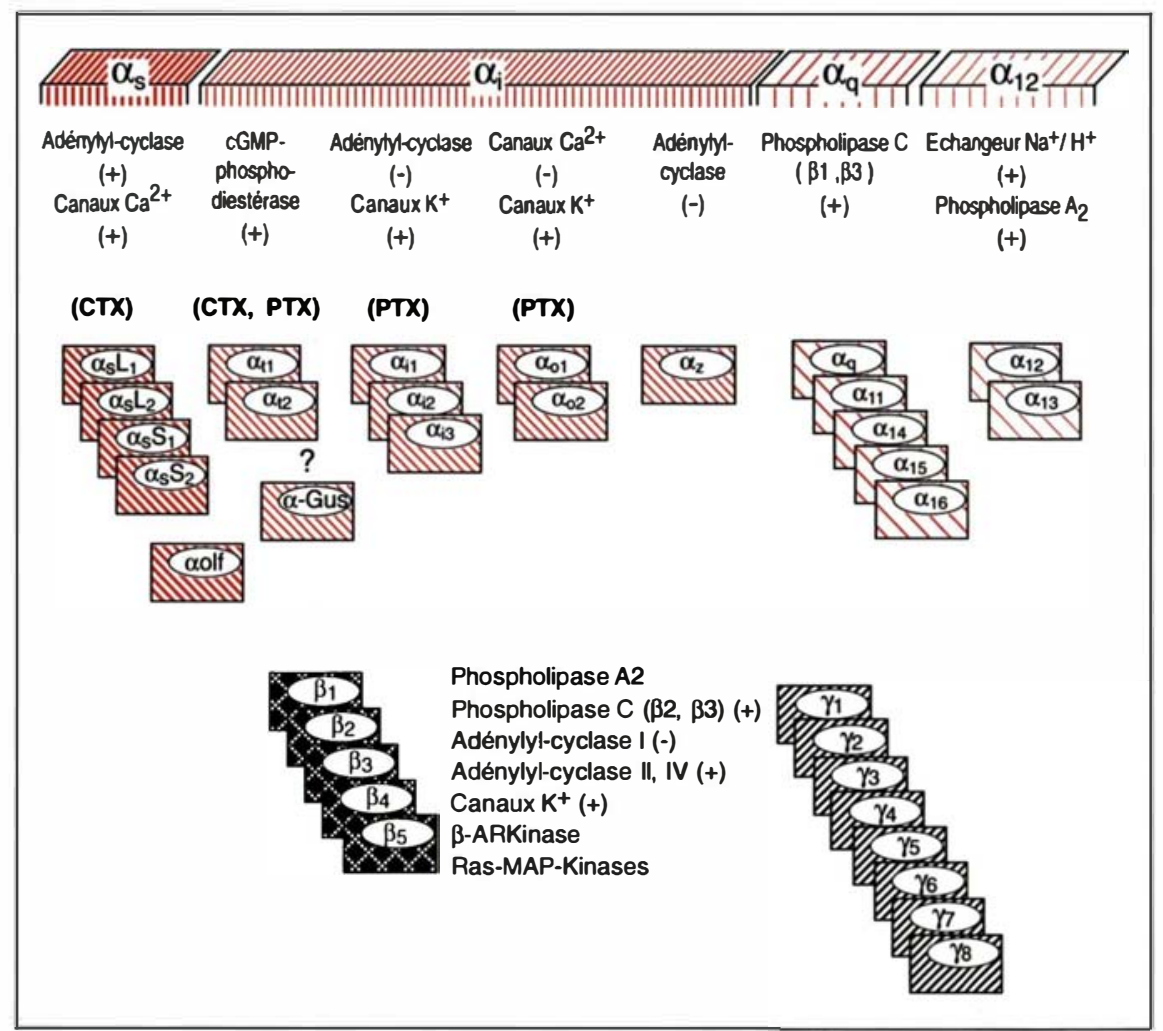

nyl (N) très conservé du domaine transmembranaire VII [3]; (b) un résidu aspartyl du domaine transmembranaire III est très conservé dans les récepteurs catécholaminergiques, sérotoninergiques et muscariniques et forme une paire intime d'ions avec l'ammonium des ligands de ces récepteurs [3] ; (c) la séquence DRY (aspartyl-arginyl-tyrosyl) ou ERW (glutamyl-arginyl-tryptophanyl) est la signature la plus claire du groupe I. Toute mutation dans cette région abolit le couplage aux protéines G [13]. Il a été proposé que l'arginine puisse jouer le rôle de commutateur en position off quand ce résidu est à l'intérieur de la poche polaire formée au sein des domaines transmembranaires et en position on lorsqu'il est tourné vers le cytosol et se lie aux protéines $G$ [13] ; (d) un résidu cystéyl, relativement bien conservé, dans la partie C-terminale juste après le domaine transmembranaire VII est palmitoylé dans les récepteurs adrénergiques (figure 2); (e) deux résidus cystéyl formant un pont disulfure (S-S) entre el et e2 (figure 2).

Le groupe II comprend un nombre beaucoup plus restreint de récep$m / s n^{\circ} 3$, vol. 11, mars 95 teurs pour des hormones peptidiques de type sécrétine, hormone parathyroïdienne (PTH), PACAP (pituitary adenylate cyclase activating polypeptide) etc. (figure 2). On ne sait pas grandchose du, ou des, domaines de ces récepteurs qui fixent ces hormones.

Le groupe III comprend une série de récepteurs du glutamate (8 gènes), dits métabotropiques [18, 19], et un récepteur fort intéressant, chargé de détecter les concentrations plasmatiques de $\mathrm{Ca}^{2+}$ au niveau des glandes parathyroïdes, et que l'on peut appeler « récepteur $\mathrm{Ca}^{2+}$ » [20].

Ces récepteurs ont en commun (figure 2): (1) la position de 20 cystéines (17 dans le domaine N-terminal, 1 dans les boucles el et e2 et 1 dans le domaine transmembranaire V); (2) un domaine conservé hydrophobe dans le domaine N-terminal; (3) $50 \%$ à $60 \%$ de résidus identiques dans les boucles internes il et i3. Ils contiennent aussi, dans le domaine $\mathrm{N}$-terminal, des séquences qui ressemblent aux protéines périplasmiques des bactéries. Ces protéines contiennent deux domaines qui trappent les acides aminés (comme les deux feuilles des Droséra qui se re-
Figure 4. Diversité et fonctions des sous-unités $\alpha$ et des dimères $\beta \gamma$ des protéines G. Si l'on considère leurs séquences primaires en acides aminés, quatre classes de sous-unités $\alpha$ peuvent être distinguées, $\alpha_{s} \alpha_{i} \alpha_{q}$ et $\alpha_{12}$. Les activités biologiques des membres de ces classes sont indiquées. (-) signifie que la sous-unité $\alpha$ inhibe et $(+)$ qu'elle stimule cette activité. Certaines sous-unités sont ADP-ribosylées par la toxine cholérique (CTX), d'autres par la toxine de Bordetella pertussis (PTX). Les complexes $\beta y$ ont des activités biologiques variées comme cela est indiqué sur cette figure. $\beta$-ARKinase: $\beta$ adrenergic receptor kinase

ferment sur un insecte s'aventurant sur leur limbe) et les transportent à la membrane bactérienne. Par analogie avec ces protéines, il a été suggéré (voir [19] pour discussion) que le glutamate et le $\mathrm{Ca}^{2+}$ se lient au domaine extracellulaire de leur récepteur et que l'ensemble bascule au niveau de la poche formée par les sept domaines transmembranaires afin d'assurer la transduction, un mécanisme similaire à celui proposé pour les récepteurs des hormones glycoprotéiques (figure 2).

La théorie suggérant que la plupart des protéines ont évolué à partir d'un petit nombre de gènes archétypes est évidemment fondée sur la notion qu'il est plus facile de dupliquer, modifier ou assembler des gènes existants que d'en former de nouveaux. La duplication et la modification ont été clairement utilisées pour engendrer les sous-groupes Ia et Ib. Dans le sous-groupe Ic et le groupe III, on peut imaginer que des gènes codant pour des protéines à sept domaines transmembranaires ont fusionné avec des gènes codant pour des protéines liant, respectivement, des hormones glycoprotéiques, le glutamate ou le $\mathrm{Ca}^{2+}$. 


\section{RÉFÉRENCES}

25. Pradier L, Ménager J, Le Guern J Bock MD, Heuillet E, Fardin V, Garret C Doble A, Mayaux JF. Septide : an agonist for the NK1 receptor acting at a site distinc from substance P. Mol Pharmacol 1994; 45 287-93.

26. Llédo P, Homburger V, Bockaert J, Vincent JD. Differential G protein-mediated coupling of D2 dopamine receptors to $K^{+}$ and $\mathrm{Ca}^{+}$channels in rat anterior pituitary cells. Neuron $1992 ; 8$ : 455-63.

27. Tang W, Gilman AG. Type-specific regulation of adenylyl cyclase by $G$ protein $\beta \gamma$ subunits. Science 1991 ; 254 : 1500-3.

28. Spengler D, Waeber C, Pantaloni C Holsboer F, Bockaert J, Seeburg PH, Jour not $\mathbf{L}$. Differential signal transduction by five splice variants of the PACAP receptor. Nature $1993 ; 365$ : 170-5.

29. Kosugi S, Okajima F, Ban T, Hidaka A Shenker A, Kohn LD. Mutation of alanine 623 in the third cytoplasmic loop of the rat thyrotopin (TSH) receptor results in a loss in the phosphoinositide but not cAMP signal induced by TSH and receptor autoantibodies. I Biol Chem 1992; $267: 24153-6$.

30. Coughlin SR. Expanding horizons for receptors coupled to $G$ proteins: diversity and disease. Curr Op Biol 1994; 6: 191-7.

31. Okamoto T, Murayama Y, Hayashi Y, Inagaki M, Ogata E, Nishimoto I. Identification of a Gs activator region of the $\beta 2$-adrenergic receptor that is autoregulated vio protein kinase A-dependent phosphorylation. Cell 1991; 67: 723-30.

32. Varrault A, Le Nguyen D, McClue $S$ Harris B, Jouin P, Bockaert J. 5-Hydroxytryptamine $_{\text {IA }}$ receptor synthetic peptides. Mechanisms of adenylyl cyclase. $J$ Biol Chem $1994 ; 269$ : $16720-5$.

33. Pin JP, Joly C, Heinemann SF, Bockaert $J$. Domains involved in the specificity of G-protein activation in phospholipase $C$ coupled metabotropic glutamate receptors. EMBO J 1994; 13: 342-8.

34. Pin JP, Waeber C, Prézeau L, Bockaert J, Heinemann SF. Alternative splicing generates metabotropic glutamate receptors inducing different patterns of calcium release in Xenopus oocytes. Proc Natl Acad Sci USA in Xenopus oocytes.

35. Crespo $P, X u N$, Simmonds WF, Gutkind JS. Ras-dependent activation of MAP kinase pathway mediated by $G$-protein $\beta \gamma$ subunits. Nature 1994; 369: 418-20.

36. Faure M, Voyno-Yasenetskaya TA, Bourne HR. CAMP and $\beta \gamma$ subunits of heterotrimeric $G$ proteins stimulate the mitogen-activated protein kinase pathways in COS-7

Les fortes analogies de séquence entre les membres d'une même famille ont permis d'isoler de nombreux ADNc ou gènes de récepteurs, déjà connus sur le plan pharmacologique ou inconnus, et que l'on a appelé des récepteurs orphelins [21]. De nombreux récepteurs ont ainsi été découverts. Parmi ceux-ci, on distingue les récepteurs dont on connaissait l'agoniste naturel (récepteur D3 dopaminergique, récepteur 5-HT6 ou 5-HT7, etc.) et les récepteurs dont on ne connaissait que des agonistes artificiels. L'exemple le plus intéressant est certainement le récepteur du cannabis dont l'ADNc a été isolé dans une banque de cerveau de rat en utilisant une sonde dérivée du récepteur de la substance-K [22]. Grâce à ce récepteur, on a pu isoler une substance, l'anandamide, qui est peut-être l'agoniste naturel du récepteur du cannabis [23].

\section{Des sites allostériques à exploiter?}

Des antagonistes non peptidiques de récepteurs peptidiques (sous-type Ib) ont été découverts par des programmes de recherche aléatoire. Ces antagonistes ont en général une forte affinité pour leurs récepteurs et une structure chimique et conformationnelle complètement différente de l'agoniste peptidique naturel. C'est, par exemple, le cas du CP 96345 qui inhibe le récepteur NK1 de la substance $\mathrm{P}$ avec un $\mathrm{Ki}$ de $14 \mathrm{nM}$ (figure3) [24]. Des mutations situées dans la partie externe des domaines transmembranaires V et VI suppriment la liaison du CP 96345 mais pas celle de la substance $P$. Cela suggère que les domaines de liaison du CP et de la substance $\mathrm{P}$ sont, au moins en partie, différents. Encore plus surprenante est l'observation qu'un analogue plus court de la substance $\mathrm{P}$, la septide $(f-$ gure 3), active ce même récepteur en se liant à un domaine différent de celui auquel se lie la substance $P$ [25]. Ces observations suggèrent qu'existent, au niveau de ces récepteurs, des sites allostériques activateurs ou inhibiteurs. Il est donc théoriquement possible d'exploiter sur le plan pharmacologique ces sites, alors que, physiologiquement, ils n'ont probablement pas de signification particulière.

\section{Une fois stimulés, les RCPG tissent leur réseau de transduction}

A l'exception du couple photon-rétinal qui n'active que la rhodopsine, les molécules messages agissent en général via plusieurs récepteurs aux propriétés pharmacologiques différentes. La sérotonine détient certainement un record puisqu'elle active treize récepteurs différents. Une fois stimulé, chacun de ces récepteurs active un réseau de transduction particulier. Il active d'abord plusieurs protéines $\mathrm{G}$ hétérotrimériques. Si l'on considère les sous-unités $\alpha$, il en existe vingt et une différentes que l'on peut regrouper en quatre familles en considérant leur séquence primaire : $\alpha_{s}, \alpha_{i}, \alpha_{q}$ et $\alpha_{12}$ (figure 4). Pour prendre un exemple, les récepteurs D2 dopaminergiques de l'hypophyse inhibent l'adénylyl cyclase (AC) via $\mathrm{G}_{\mathrm{i} 2}$, inhibent les canaux $\mathrm{Ca}^{2+}$ dépendants du voltage via $\mathrm{G}_{\mathrm{o}}$ et activent les canaux $\mathrm{K}^{+}$dépendants du voltage via $\mathrm{G}_{\mathrm{i3}}$ [26]. La complexité s'accroît si l'on note que chaque sous-unité $\alpha$ active ou inhibe un ou plusieurs effecteurs (figure 4) qui, eux-mêmes, existent sous plusieurs formes. Il existe huit gènes codant l'AC. Chacune de ces enzymes a une régulation particulière. L'AC de type I est activée par $\alpha$ s et par le complexe $\mathrm{Ca}^{2+}$-calmoduline agissant en synergie. Elle sera donc particulièrement active s'il existe dans la même cellule des récepteurs agissant via $\mathrm{G}_{\mathrm{s}}$ et d'autres qui augmentent la concentration intracellulaire en $\mathrm{Ca}^{2+}$ [27]. Les $\mathrm{AC}$ de type II ou IV sont particulièrement activées par $\alpha_{\mathrm{s}}$ en présence de fortes concentrations de $\beta \gamma$ que seule la stimulation de $G_{i}$ ou de $G_{0}$ peut libérer. La coactivation d'un récepteur stimulant $G_{s}$ et d'un récepteur stimulant $G_{i}$ (ce dernier agissant seul inhiberait ces $A C)$ produira une stimulation de ces deux types particuliers d'AC, supérieure à celle qui aurait été produite par la seule stimulation de $\mathrm{G}_{\mathrm{s}}$ [27]. On peut imaginer les régulations extrêmement fines que ces systèmes d'activations coïncidantes peuvent engendrer. Comme nous l'avons vu (figure 1), les sous-unités $\beta \gamma$ libérées lors de la stimulation des protéines G par les RCPG ont aussi de nombreux effecteurs physiologiques 


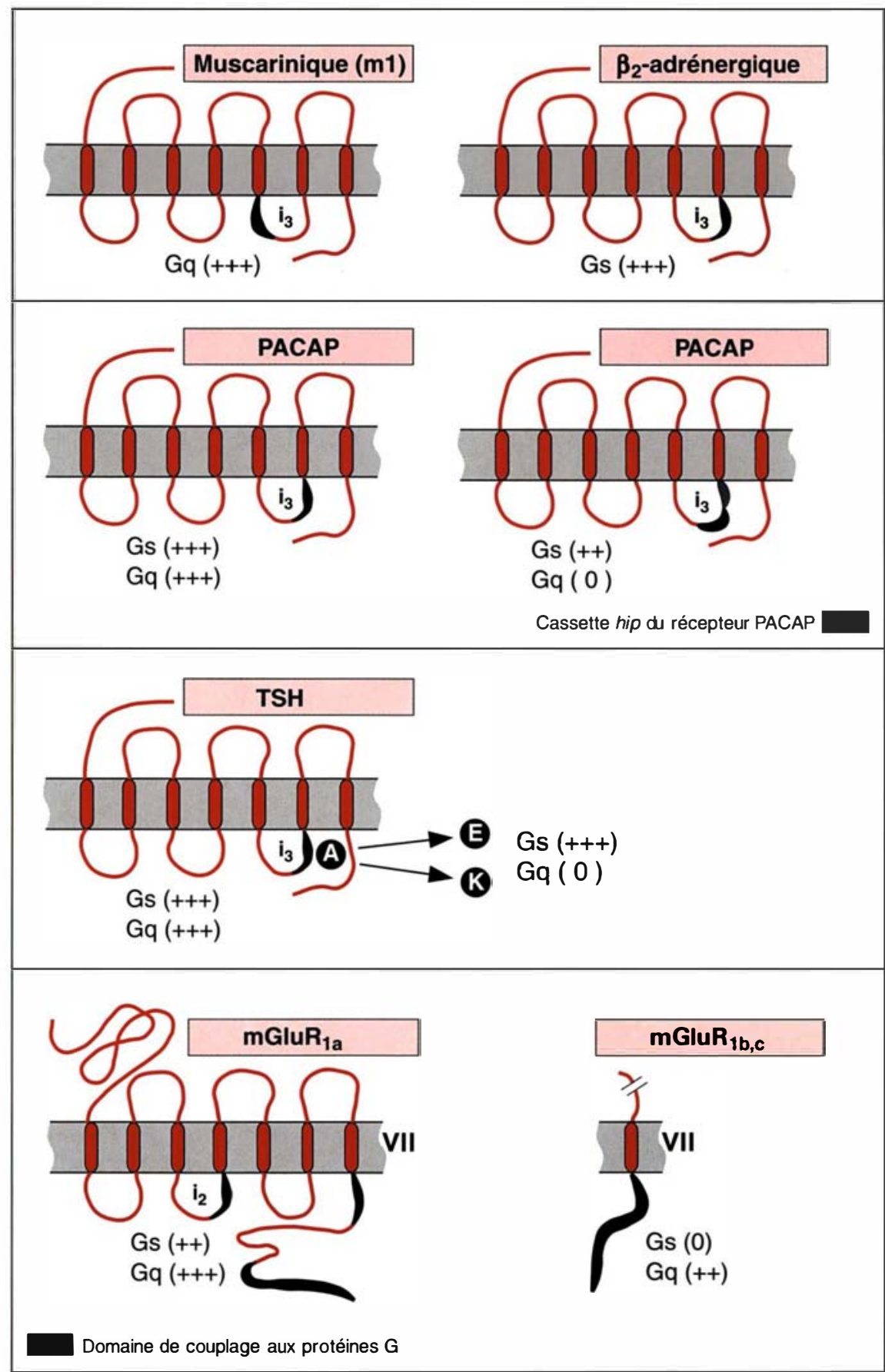

(figure 4). Un des effecteurs de $\beta \gamma$ est particulièrement intéressant, il s'agit de la voie Ras-MAP-kinase sur laquelle nous reviendrons plus loin.

Nous ne pouvons pas développer dans le cadre de cette revue tous les aspects structuraux concernant les interactions récepteurs/protéines G, d'une part, et protéines G/effecteurs, d'autre part. Nous allons cependant dire quelques mots des do$m / s n^{\circ} 3$, vol. 11, mars 95 maines structuraux par lesquels les RCPG activent les protéines G. Cela pour deux raisons: premièrement, parce que ces domaines sont le siège d'épissages alternatifs qui augmentent encore la finesse des interactions, d'autre part, parce que des mutations dans ces domaines modifient profondément l'activité des RCPG et sont retrouvées dans de nombreuses affections.
Figure 5. Domaines des RCPG impliqués dans le couplage aux protéines G. Dans la plupart des RCPG, la boucle i3 dans sa partie $N$-terminale (muscarinique-m1) ou dans sa partie $C$-terminale $\left(\beta_{2}\right.$-adrénergique; récepteurs PACAP, récepteurs TSH) est impliquée dans le couplage aux protéines $G\left(G_{s}\right.$ ou $G_{q}$ dans les exemples choisis). Une cassette hip introduite par épissage alternatif au niveau de i3 dans le récepteur PACAP supprime son couplage à $G_{q}$, alors que son couplage à $G_{s}$ est maintenu. Une mutation dans i3 du récepteur TSH (résidu alanyl (A), en résidu glutamyl (E) ou résidu lysyl (K), supprime le couplage à $G_{a}$ mais maintient le couplage à $G_{s}$. Dans les récepteurs métabotropiques du glutamate (mGluR1a), c'est la boucle i2, associée à des domaines de la partie C-terminale située après le domaine transmembranaire VII, qui assure le couplage à $G_{s}$ et $G_{a}$. Les variants d'épissage mGluR1b et mGluR1c, ayant un domaine $C$-terminal plus court que celui de mGluR1a, stimulent $G_{q}$ mais pas $G_{s}$

Dans la plupart des récepteurs des groupes I et II, les domaines les plus importants pour le couplage aux protéines $G$ sont localisés dans la boucle i3 et plus particulièrement aux extrémités de cette boucle [12] (figure 5). La boucle i2 et le domaine C-terminal, bien que moins essentiels, jouent un rôle important dans la spécificité et la qualité des interactions. Le récepteur PACAP illustre bien l'impor- 


\section{RÉFÉRENCES}

37. Touhara $\mathrm{K}$, Inglese J, Pitcher JA, Shaw G, Lefkowitz RJ. Binding of $G$ protein $\beta \gamma$-subunits to pleckstrin homology domains.J Biol Chem 1994; 269: 10217-20.

38. Kjelsberg MA, Cotecchia S, Ostrowski J, Caron MC, Lefkowitz RJ. Constitutive activation of the $\alpha_{18}$-adrenergic receptor by all amino acid substitutions at a single site. $J$ Biol Chem 1992; 267: 1430-3.

39. Lefkowitz RJ, Cotecchia S, Samana P, Costa T. Constitutive activity of receptors coupled to guanine nucleotide regulatory proteins. Trends Pharmacol Sci 1993; 14: 303 4.

40. Barker EL, Westphal RS, Schmidt D, Sanders-Busch E. Constitutively active 5-hydroxytryptamine $_{2 \mathrm{c}}$ receptors reveal novel inverse agonist activity of receptor ligands. J Biol Chem 1994; 269: 11687-90.

41. Costa T, Herz A. Antagonists with negative intrinsic activity at $\delta$ opioid receptors coupled to GTP-binding proteins. Proc Natl Acad Sci USA 1989; 86: 7321-5.

42. Götze K, Jakobs KH. Unoccupied $\beta$-adrenoceptor-induced adenylyl cyclase stimulation in turkey erythrocyte membranes. EurJ Pharmacol 1994 ; 268: 151-8.

43. Parma J, Duprez L, Van Sande J, Cochaux P, Gervy C, Mockel J, Dumont J', Vassart G. Somatic mutations in the thyrotropin receptor gene cause hyperfunctioning thyroid adenoma. Nature $1993 ; 365$ : 649-51.

44. Maenhaut C, Pirson I, Baptist $M$, Lamy F, Miot F, Roger P, Dumont JE. La cascade mitogène de l'AMPc dans la thyroìde et dans d'autres tissus. médecine/sciences 1995 ; 11 : 204-14.

45. Van den Ouweland AMW, Dreesen JCFM, Verdiik M, Knoers NVAM, Monnen LAH, Rocchi M, Van Oost BA. Mutations in the vasopressin type 2 receptor gene (AVPR2) associated with nephrogenic diabetes insipidus. Nature Genet 1992 ; 2: 99-102.

46. Spiegel AM, Weinstein LS, Shenker A Abnormalities in $G$ protein-coupled signal transduction pathways in human disease. Clin Invest 1993; 92: 1119-25.

47. Iiri T, Herzmark P, Nakamoto JM, Van Dop C, Bourne H. Rapid GDP release from $\mathrm{G}_{\mathrm{se}}$ in patients with gain and loss of endocrine function. Nature 1994; 371 : 1647.

48. Chabre $O$. Une mutation de la protéine $\mathrm{G}_{\mathrm{s \alpha}}$ responsable d'hyper- et d'hypofonctionnements endocrines. médecine/sciences 1995 . 11: 105-8.

49. Saudou F, Amara D, Dierich A, Le MeurM, Ramboz S, Segu L, Buhot M, Hen R. Enhanced aggressive behavior in mice lacking 5-HT $1 \mathrm{~B}$ receptor. Science 1994; 265 . 1875-8.

50. Mollon J. Colour vision. Worlds of difference. Nature 1992; 356: 378-9.

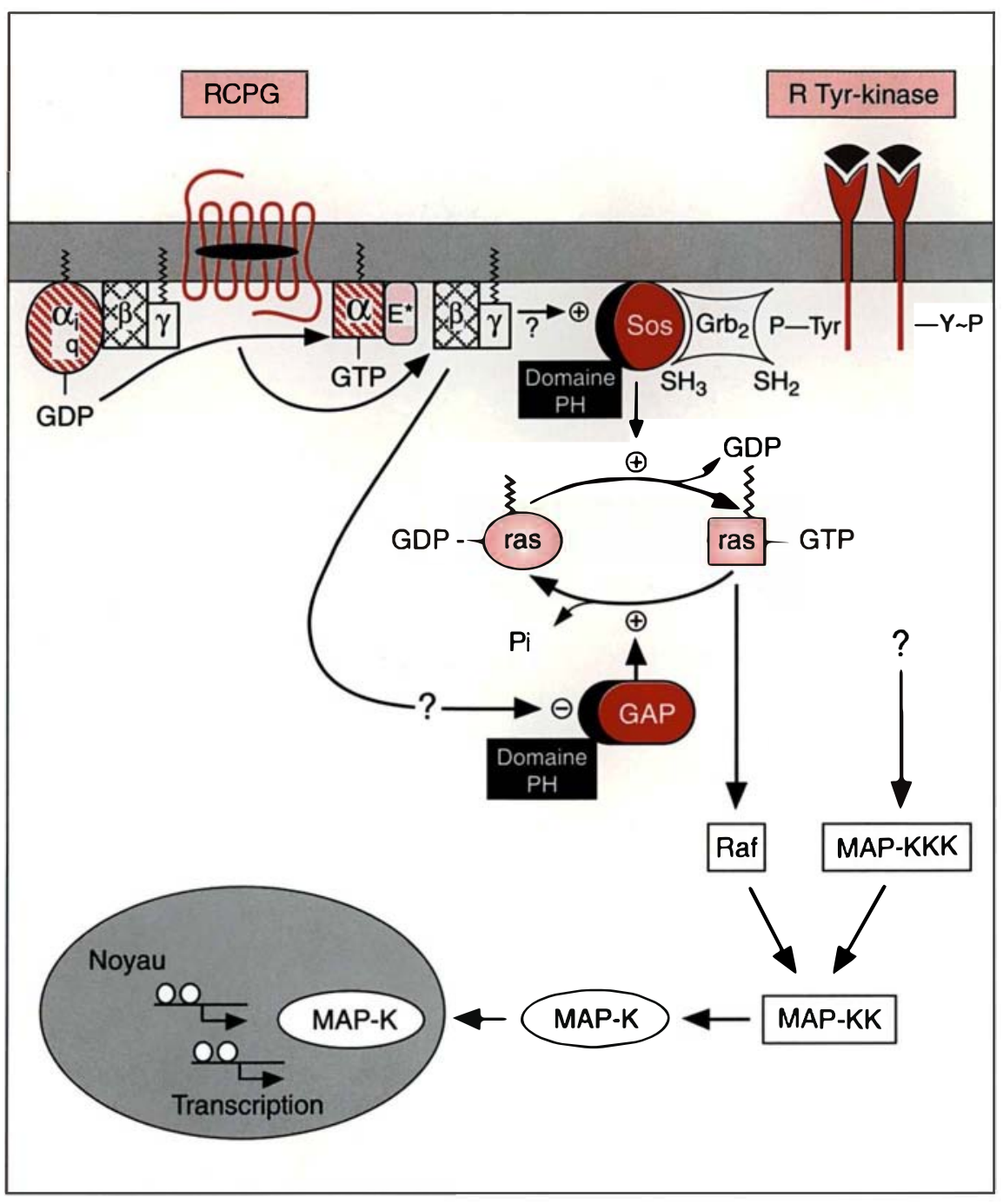

Figure 6. Contrôle des signaux mitogènes par les RCPG et les R-tyrosine-kinases. On sait que l'activation des récepteurs $(R)$ tyrosine kinases entraîne leur autophosphorylation. Une des tyrosines phosphorylées est reconnue par le domaine SH2 de Grb2. Les deux domaines SH3 de Grb2 interagissent avec le facteur d'échange Sos lou d'autres facteurs d'échanges comme Ras GRF). Le complexe Grb2-Sos catalyse l'échange GDP $\rightarrow$ GTP de Ras. Ras-GTP active la protéine kinase Raf. Raf peut activer, par phosphorylation, la MAPkinase-kinase (MAP-KK) qui peut être aussi activée par la MAP-kinase-kinasekinase (MAP-KKK). MAP-KK active par phosphorylation les MAP-kinases (MAP-K) qui pénètrent dans le noyau pour phosphoryler des facteurs de transcription contrôlant la division cellulaire. Les RCPG activent aussi Ras par l'intermédiaire de $\beta \gamma$. $\beta \gamma$ activerait Sos ou inhiberait GAP (GTP activating protein) en interagissant avec leur domaine PH (domaine d'homologie avec la Pleckstrine, substrat majeur de la PKC dans les plaquettes). 


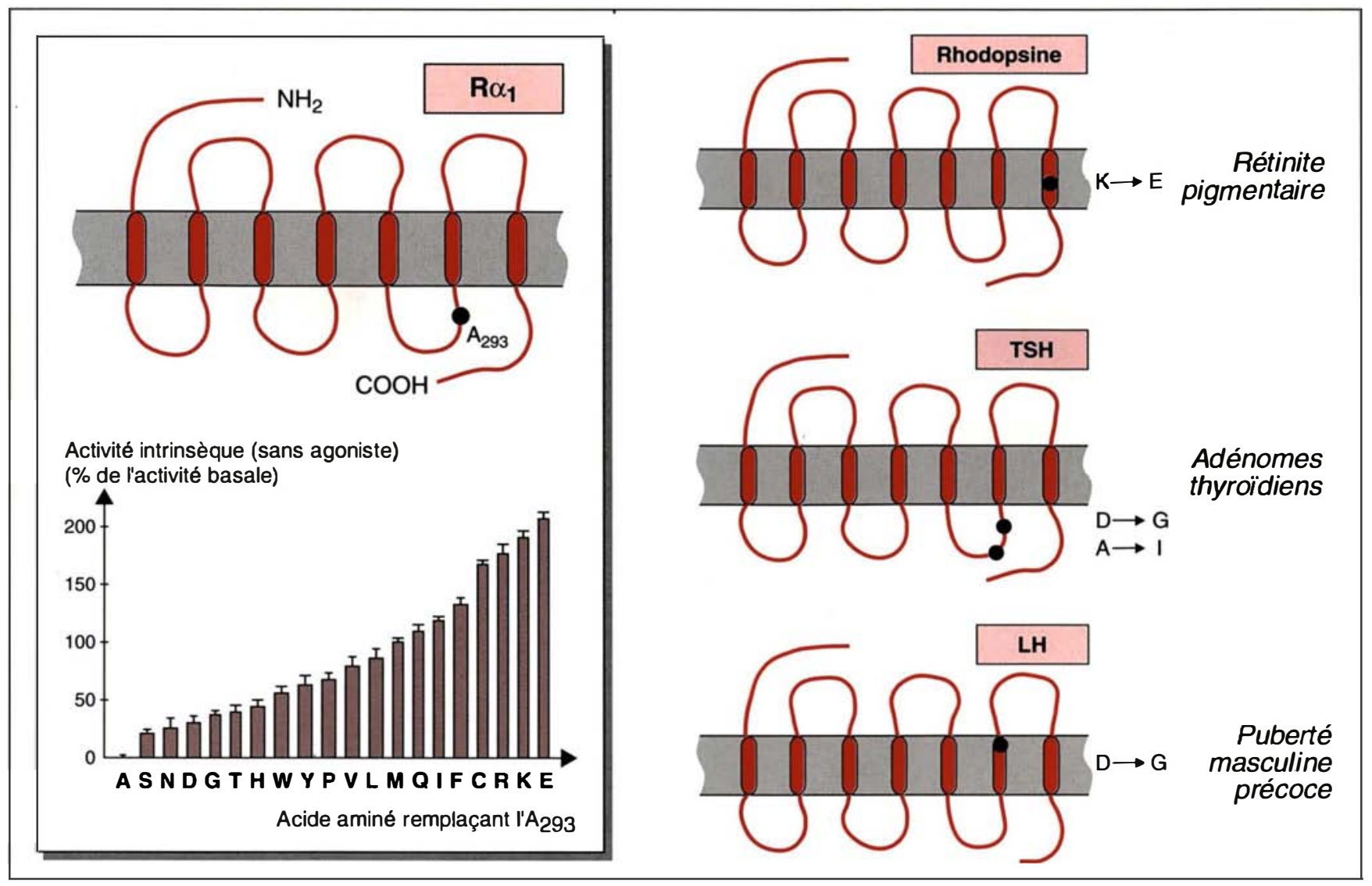

Figure 7. Mutations activatrices des RCPG. Le remplacement de l'alanyl (A) 293 de la boucle i3 des récepteurs $\alpha_{1}$-adrénergiques par l'un quelconque des 19 autres acides aminés entraîne une augmentation de l'activité intrinsèque (sans agoniste) du récepteur. Lorsque cet acide aminé est le glutamate (E), l'activité intrinsèque est comparable à l'activité du récepteur natif en présence de noradrénaline. (Adapté de [36].) A droite, mutations activatrices de récepteurs entraînant des affections diverses.

tance de la partie C-terminale de la boucle i3. Ce récepteur existe sous cinq formes d'épissage qui se distinguent par la nature et l'intensité de leur couplage aux protéines G. La forme la plus simple est couplée efficacement à $\mathrm{G}_{\mathrm{s}}$ (stimulation de l'AC) et $G_{q}$ (stimulation de la PLC) (figure 5). La forme d'épissage dans laquelle une cassette dite hip est présente au niveau de la partie C-terminale de la boucle i3, active $\mathrm{G}_{\mathrm{s}}$ mais pas $G_{q}$ (figure 5) [28]. La présence d'une cassette hop n'a que peu de conséquences sur les couplages. En revanche, la présence simultanée des deux cassettes hip et hop donne un profil intermédiaire (mauvais couplage à $G_{s}$ et à $G_{q}$ ) [28]. Beaucoup d'autres expériences désignent cette région comme étant importante $m / s n^{\circ} 3$, vol. 11, mars 95 pour le couplage aux protéines $G$ (voir [12]) : (1) la mutation, dans le récepteur $\mathrm{TSH}$, d'une alanine $(\mathrm{A})$ de cette région en glutamate $(\mathrm{E})$ ou lysine $(K)$, supprime le couplage de ce récepteur à $G_{q}$ tout en maintenant son couplage à $G_{\mathrm{s}}$ (figure 5) [29]. D'autres mutations de ce récepteur, mais aussi d'autres récepteurs dans cette région, entraînent leur activation constitutive [30] (voir ci-après); (2) des peptides d'une quinzaine d'acides aminés correspondant à des fragments de la fin de la boucle i3 du récepteur $\beta 2$-adrénergique et du récepteur 5-HT1A stimulent directement les protéines $G$ [31,32].

Dans le groupe III, ce sont les parties C-terminales de i2 et le domaine Cr terminal situé après le domaine transmembranaire VII qui sont déter- minants pour le couplage aux protéines $G_{q}$ et $G_{s}$ [33]. Deux formes d'épissage du récepteur mGluR1, ayant un domaine C-terminal plus court, stimulent moins bien $\mathrm{Gq}$ et plus du tout $\mathrm{G}_{\mathrm{s}}$ (figure 5) [34].

\section{Quand les RCPG et les récepteurs tyrosine kinases partagent une cible commune, p21ras}

Un des exemples les plus frappants de l'évolution de nos connaissances sur les mécanismes de transduction des récepteurs membranaires et de l'interdépendance de ces mécanismes est illustré par la découverte récente que le contrôle de la division cellulaire par les RCPG et par les récepteurs tyrosine kinases emprunte 
une voie commune passant par l'activation de Ras et des MAP-kinases. Les mécanismes par lesquels les récepteurs tyrosine kinases activent la petite protéine Ras sont illustrés sur la $f i$ gure 6 et ont fait l'objet d'une revue récente [7]. On savait depuis longtemps que certains RCPG, couplés à $\mathrm{G}_{\mathrm{i}} / \mathrm{G}_{\mathrm{o}}$, étaient de puissants mitogènes, seuls ou associés à la stimulation de récepteurs tyrosine kinases. Deux articles récents montrent que ces RCPG sont vraisemblablement mitogènes parce qu'ils activent Ras par l'intermédiaire de $\beta \gamma[35,36]$. Deux hypothèses peuvent être proposées pour expliquer comment $\beta \gamma$ active $\mathrm{p} 21^{\text {ras }}$. La première est que $\beta \gamma$ active Sos, l'autre est que $\beta \gamma$ inhibe GAP (figure 6)[7]. Les deux hypothèses peuvent être proposées puisque Sos et GAP possèdent des domaines dits PH (domaines d'homologie avec la pleckstrine, substrat majeur de la PKC dans les plaquettes) auxquels $\beta \gamma$ peut se lier [37].

\section{RCPG et pathologie}

Il y a de nombreuses possibilités d'altérations des protéines intervenant dans la transduction des RCPG pouvant conduire à des maladies diverses. Ces altérations peuvent affecter les récepteurs eux-mêmes, les protéines G, les effecteurs et concerner la sur- ou la sous-expression de ces protéines ou encore leurs mutations. Nous ne considérerons que les mutations dans cette revue parce que des découvertes récentes et spectaculaires ont été faites dans ce domaine. Nous avons déjà discuté l'importance du domaine C-terminal de la boucle i3 dans le couplage aux protéines $G$ en omettant une série d'expériences de mutagenèse d'acides aminés conservés de ce domaine. Par exemple, le remplacement de l'alanine 293 dans le récepteur $\alpha 1$-adrénergique [38] par l'un quelconque des 19 autres acides aminés confère au récepteur muté une activité intrinsèque (figure 7) [38]. Cela signifie qu'il stimule son effecteur même en l'absence d'agoniste. Lorsque le glutamate (E) remplace l'alanine, l'activité intrinsèque du récepteur devient voisine de celle obtenue après stimulation optimale avec l'adrénaline [38]. Cette expérience, et d'autres si- importantes : (1) il semble que la séquence native de la partie C-terminale de i3 soit celle qui donne l'activité intrinsèque la plus basse. En conséquence, on peut proposer qu'elle maintient le récepteur dans un état contraint. L'activation du récepteur consisterait alors à introduire une modification conformationnelle relativement minime au niveau de ce domaine; (2) il est possible que certains récepteurs, même natifs, aient une activité intrinsèque [39]. Cela semble être le cas des récepteurs 5-HT2 [40], des récepteurs $\delta$ des opiacés [41], des récepteurs $\beta$-adrénergiques [42] et des récepteurs mGluRla (Pin et al., manuscrit en préparation); (3) des produits ont été trouvés qui inhibent cette activité intrinsèque physiologique ou pathologique. C'est le cas de certains antagonistes des récepteurs $\beta$-adrénergiques, des récepteurs des opiacés [41] ou des récepteurs 5HT2 [40]. Ces produits sont en fait des "agonistes inverses" $\left(\mathrm{m} / \mathrm{s} n^{\circ} 10\right.$, vol. 10, p. 1011). Cette notion pharmacologique, que l'on connaissait pour les récepteurs GABA/benzodiazépines, est nouvelle pour les RCPG (4) des mutations dans cette région devraient être à l'origine de troubles dont les symptômes seraient ceux que l'on attend d'une hyperstimulation du récepteur non muté. On a effectivement trouvé: (a) des mutations somatiques dans le domaine C-terminal de la boucle i3 des récepteurs TSH dans certains adénomes thyroïdiens humains (3 sur 11 étudiés). Les mutations concernent une alanine mutée en isoleucine et un aspartate muté en glycine (figure 7) (m/s $n^{\circ}$ 12, vol. 9, p. 1421) [43]; (b) une mutation (autosomique dominante) de la rhodopsine au niveau de la lysine (K) 296 du domaine transmembranaire VII sur laquelle est fixé le rétinal qui entraîne une rétinite pigmentaire (figure 7)[30] ; (c) une mutation autosomique dominante d'un aspartate (D) en glycine (G) au niveau du domaine transmembranaire VI dans le récepteur LH (figure 7) [30]. Cette mutation entraîne une puberté masculine précoce [44]; les raisons pour lesquelles elle entraîne une activité constitutive du récepteur ne sont pas connues.

En dehors de ces mutations activatrices, il existe de nombreuses mutations inactivant les RCPG conduisant à des maladies diverses et que nous avons résumées (figure 8) (voir aussi [30]). Dans le cas de la rhodopsine et du récepteur de la vasopressine V2, de nombreuses mutations de natures différentes et invalidant toute la protéine, ont été trouvées, conduisant respectivement à une rétinite pigmentaire et au diabète insipide $\left(m / s n^{\circ} 2\right.$, vol. $8, p .171$ et $n^{\circ} 9$, vol. 8 , p. 1004). La figure 8 indique les différents types de mutations conduisant à l'invalidation du récepteur de la vasopressine V2 [45].

\section{Protéines $\mathbf{G}$ et pathologie}

La structure cristallographique des protéines $\alpha$ a confirmé l'importance de cinq domaines distincts appelés G1, 2, 3, 4, 5 impliqués dans la liaison du GDP et GTP $[8,12]$. La région qui subit le changement conformationnel le plus important lors de la fixation du GTP est la région G2-G3 (désignée par $\triangle$ GTP dans la figure 9). Étant donné l'importance de ces régions dans l'activation de ces protéines, il n'est pas étonnant qu'elles soient le site de modifications chimiques ou de mutations conduisant à l'expression de maladies [28] (figure9).

\section{Modifications covalentes}

La première maladie au cours de laquelle le rôle d'une protéine $\mathrm{G}$ a été clairement établi fut le choléra. Une exotoxine libérée par le Vibrio cholerae catalyse l'ADP-ribosylation de l'arginine (R) 201 d' $\alpha_{\mathrm{s}}$ localisée dans le domaine G2. Cette modification covalente entraîne une inhibition de l'activité GTPase, une activité persistante d' $\alpha_{\mathrm{s}}$ et une production excessive d'AMPc. La bactérie restant au niveau intestinal, la production excessive d'AMPc provoquera des diarrhées sévères dues à l'inversion des transports d'eau et de chlore. Une modification covalente analogue est catalysée par la toxine de la coqueluche (Bordetella pertussis) au niveau d'une cystéine localisée au niveau du domaine C-terminal d' $\alpha_{i}$ et d' $\alpha_{0}$. Cette modification découple ces protéines $\alpha$ de leurs récepteurs et pourrait être à l'origine des effets hypoglycémiants observés dans la coqueluche (suppression du contrôle 


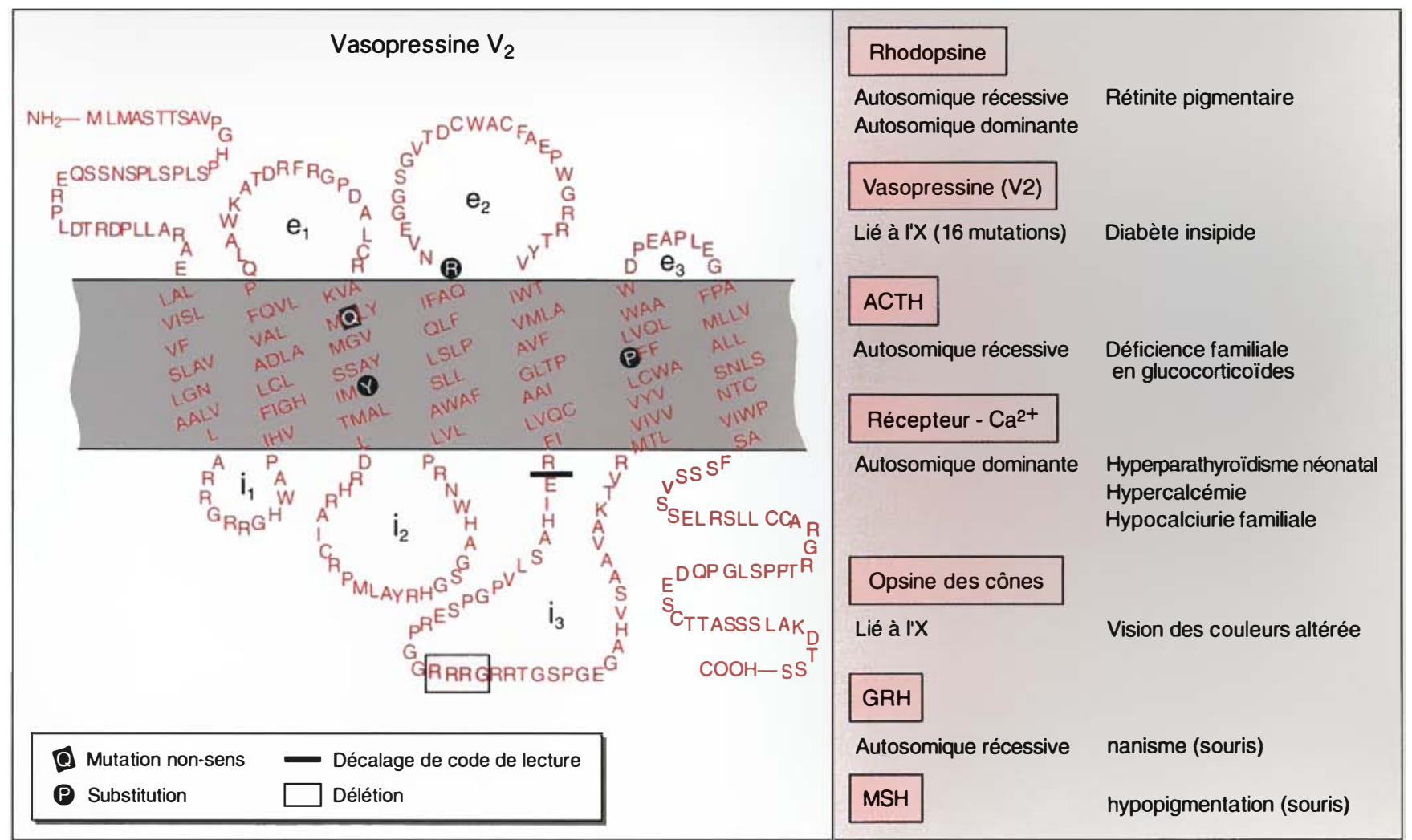

Figure 8. Mutations inhibitrices des RCPG. A gauche, diverses mutations trouvées dans le récepteur de la vasopressine (V2) provoquant un diabète insipide néphrogénique (résistant à la vasopressine). A droite, caractéristiques des mutations trouvées dans des RCPG et les maladies associées.

inhibiteur des récepteurs $\alpha_{2}$-adrénergiques sur la sécrétion d'insuline).

\section{Mutations somatiques}

Dans certaines cellules, l'AMPc stimule la division cellulaire. C'est le cas des cellules somatotropes de l'hypophyse sécrétant l'hormone de croissance [44]. Dans des tumeurs de ces cellules provoquant une acromégalie, des mutations somatiques dominantes d' $\alpha_{\mathrm{s}}$ ont été trouvées. Il s'agit de mutations de l'arginine (R) 201 en cystéine $(C)$ ou histidine $(H)$ (figure 9) ou de mutations de la glutamine (Q) 227 du domaine G3 en arginine $(\mathrm{R})[8,46]$. Cette dernière mutation prolonge l'activation d' $\alpha$ s et réduit son activité GTPasique. Nous avons vu (figure 6) que la stimulation d' $\alpha_{i}$ peut stimuler la division cellulaire via $\beta \gamma$. Il n'est donc pas étonnant de trouver des mutations d' $\alpha_{i}$ dans certaines tumeurs ovariennes ou cortico-surrénaliennes. Ces tumeurs concernent principale$m / s n^{\circ} 3$, vol. 11 , mars 95 ment l'arginine $(R)$ du domaine $G 2$ (figure 9) $[8,46]$. Dans la maladie de McCune-Albright $\left(m / s ~ n^{\circ} 2\right.$, vol. $8, p$. 184), maladie se traduisant par des désordres endocriniens multiples, une pigmentation café au lait, des ossifications sous-cutanées, une mutation en mosaïque intéressant l'arginine (R) 201 d' $\alpha_{s}$ a été trouvée $[8,46]$.

\section{Mutations génétiques}

Dans le pseudohypoparathyroïdisme (PHP), notamment de type Ia encore appelé l'ostéodystrophie héréditaire d'Albright (résistance à l'action d'hormones PTH, TSH, etc.) $(\mathrm{m} / \mathrm{s}$ $n^{\circ} 7$, vol. 6, p. 708), plusieurs mutations d' $\alpha_{\mathrm{s}}$ intéressant l'arginine $201(\mathrm{R})$ conduisent à une réduction de $50 \%$ de la concentration d' $\alpha_{\mathrm{s}}$ [46]. Enfin, une mutation d' $\alpha_{\mathrm{s}}$ intéressant une alanine (A366 mutée en sérine) du domaine G5 a été décrite récemment chez deux patients souffrant d'un PHP de type Ia et d'une puberté précoce par sécrétion de tes- tostérone en l'absence d'hormone lutéotrope $\left(\mathrm{m} / \mathrm{s} n^{\circ} 11\right.$, vol. $10, p$. 1177) $[47,48]$. Cette mutation a deux effets : (1) un relargage rapide du GDP qui entraîne une activation constitutive d' $\alpha_{s}$, responsable d'une hyperproduction d'AMPc; (2) une dégradation de la protéine à $37^{\circ} \mathrm{C}$ qui entraîne son inactivation. On comprend que la mutation entraîne une hyperactivité d' $\alpha_{\mathrm{s}}$ au niveau des testicules dans lesquels la température est de $33{ }^{\circ} \mathrm{C}$ (sécrétion de testostérone dépendante de l'AMPc, au niveau des cellules de Leydig) et une hypoactivité d' $\alpha_{\mathrm{s}}$ au niveau des tissus dont la température est de $37^{\circ} \mathrm{C}$ (notamment résistance à la $\mathrm{PTH}$ et à la TSH) [48].

\section{Futures directions}

Si l'on considère l'importance et la diversité des systèmes de communications contrôlés par les RCPG on peut certainement affirmer que seules quelques-unes des affections associées 


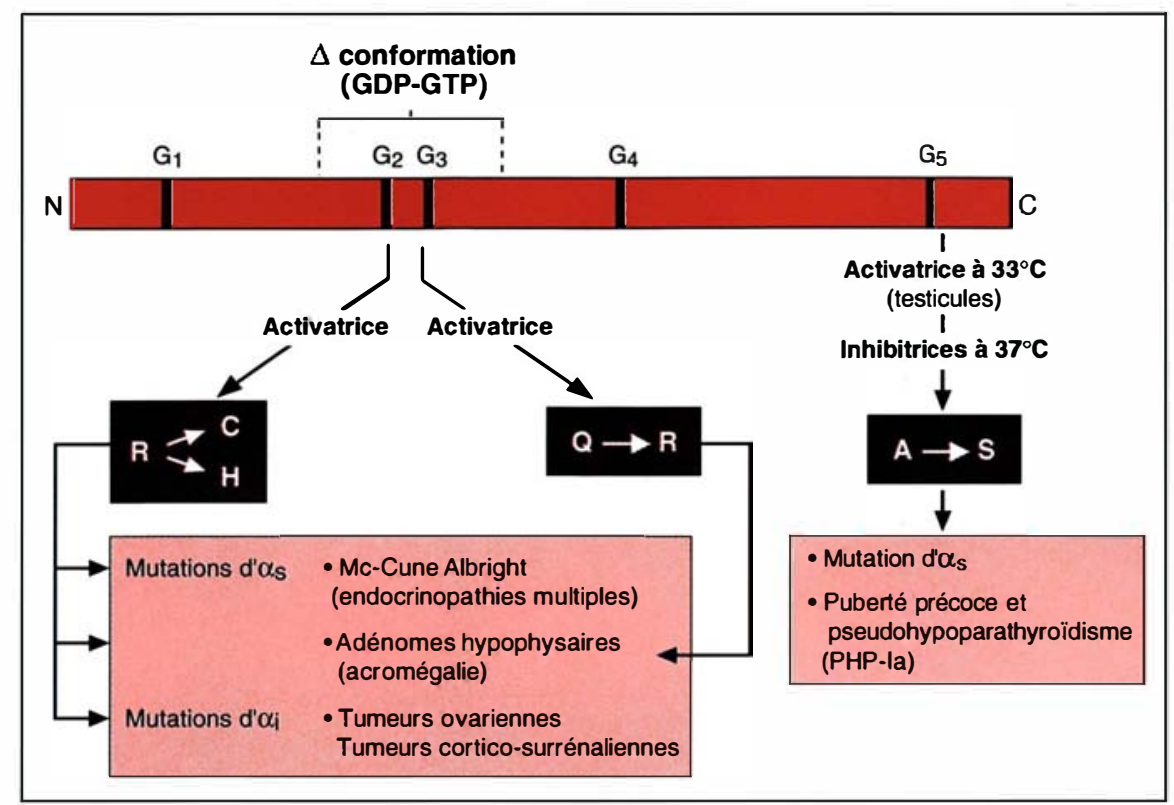

Figure 9. Mutations affectant les protéines $\boldsymbol{G}$ et les maladies associées. $G 1$ à G5 sont les domaines des sous-unités $\alpha$ liant le GTP. La région G2-G3 est celle qui subit le changement de conformation le plus important lors de l'échange GDP $\rightarrow$ GTP.

à leur dysfonctionnement ou à celui des protéines qui leur sont associées (principalement les protéines G) ont été décrites. Par exemple, il était évident de rechercher des mutations du récepteur de la vasopressine chez les malades souffrant d'un diabète insipide résistant à cette hormone ou de la rhodopsine chez ceux souffrant de rétinite pigmentaire. En revanche, on peut penser qu'il existe des mutations plus difficiles à détecter, comme celles qui réduiraient l'activité de récepteurs du système nerveux central impliqués dans le contrôle des émotions ou des comportements. En effet, de telles mutations ou dysfonctionnements ne devraient pas entraîner des troubles immédiatement et facilement reconnaissables. Une bonne illustration en est donnée par la récente invalidation du gène codant pour le récepteur 5-HT1B [49]. Les souris déficientes vivent normalement, à l'exception d'une tendance agressive et anxieuse lors de situations particulières. L'invalidation de gènes codant pour les RCPG est certainement une bonne méthode pour repérer ceux dont la mutation entraîne une maladie qui n'a pas de lien ces récepteurs. En revanche, nos connaissances de ces systèmes de transduction permettent certainement de pronostiquer leur intervention dans diverses maladies déjà connues. Par exemple, certains RCPG présentant des mutations constitutives pourraient être, vu leur action sur la voie Ras-MAP-kinase, des oncogènes potentiels. Dans une telle situation, des agonistes inverses seraient théoriquement utilisables pour en contrôler les effets pathogènes.

Finalement, il est possible que les variations normales (polymorphisme) des protéines impliquées dans les systèmes de transduction soient associées à des différences physiologiques significatives. La différence dans la perception des couleurs chez des individus ayant des pigments visuels ne différant que d'un seul acide aminé en est une excellente démonstration [50]. Des formes polymorphiques des récepteurs D4 humains et des récepteurs $\beta 2$-adrénergiques ont aussi été décrites [17]. Les conséquences physiopathologiques qui leur sont éventuellement associées ne sont pas connues

\section{Summary}

The seven-transmembrane receptors : physiology and pathology of transduction

The membrane-bound receptors can be classified into a small number of families and the largest family is composed of receptors coupled to $G$ proteins (GPCR). This family contains several hundred members, able to recognize various messages (such as photons, ions, amino acids, etc.). These GPCR are monomeric proteins possessing a common topology, similar to that of rhodopsine, comprising 7 transmembrane domains (TD). They can be subclassified into three groups and have no homology in their primary sequence. The localization of the ligand binding domain lies within the TDs (rhodopsin, $\beta_{2}$-adrenergic receptor...) and more or less within the external N-terminal domain. GPCRs catalyse the GDP/GTP exchange on trimeric $G$ proteins $(\alpha \beta \gamma)$. They control a network of transductions either via the $\alpha$ subunits of these $G$ proteins or via the $\beta \gamma$ dimers (in particular Ras protein activation). Activating or inactivating mutations of these GPCRs have been described to cause pathologies such as retinitis pigmentosa, thyroid adenoma, precocious puberty or diabetes insipidus or familial glucocorticoid deficiency. Apart from these mutations, polymorphism in the genes coding GPCRs, may be at the origin of individual differences, in particular in receptors controlling sensory perception and other functions of the nervous system.

\section{TIRÉS À PART}

J. Bockaert. 